\title{
One of the main problems
}
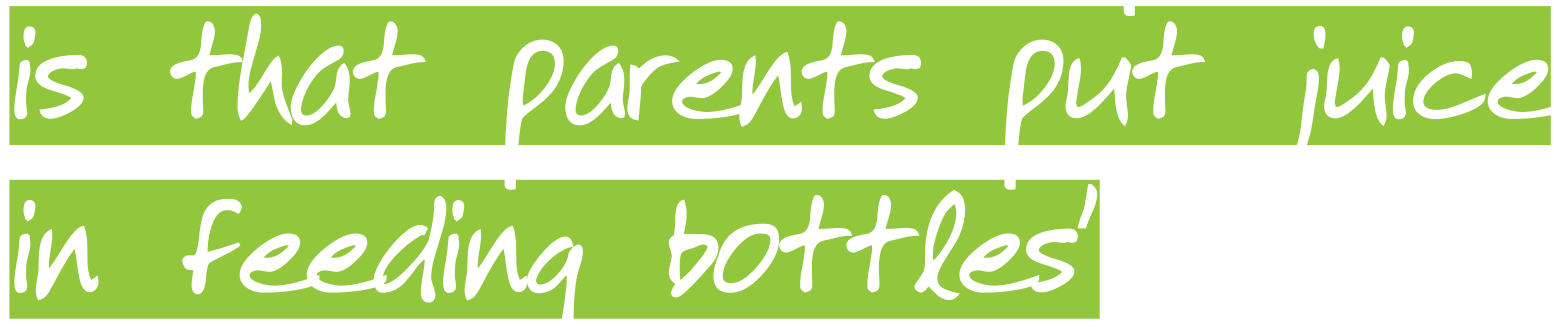

Role: Health visitor

Description: Registered nurses or midwives who undertake further (postregistration) health visitor training at degree level. Health visitors work as part of a primary healthcare team, assessing the health needs of individuals, families and the wider community.

Regulator: Qualified health visitors are regulated by the Nursing and Midwifery Council. To register you have to have at least 450 hours of registered practice within three years. You are also expected to do at least 35 hours of CPD over three years and must keep a portfolio of evidence which the Council might ask to see at any time.

May work with: Midwives; GPs; speech and language therapists; audiology specialists; social workers; dental professionals who might visit clinics to manage dental health promotion or supply promotional packs to health visitors; school nurses; hospital child development teams.

\section{Case study}

Ann is a part-time health visitor based in Greater Manchester. Ann has 14 years' experience as a health visitor and loves the challenge of using the varied skills needed to support and educate families from pregnancy to school age. Ann mostly deals with vulnerable families, helping them make informed choices about their child's health and instilling good health habits early on.

A decline in the number of health visitors over the past few years poses a threat to the profession's aims of promoting health and reducing inequalities, as some families have missed out on the wide range of benefits health visiting teams offer; however, David Cameron has pledged that an extra 4,200 health visitors will be recruited across England by 2015 .

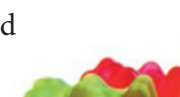

\section{Dental professionals are experts in giving oral health advice and education and knowing} what is best for teeth. But what do other health professionals advise patients when it comes to the oral cavity? In the first of a new series for Vital, Laura Pacey spoke to a health visitor to find out.

\section{Laura: Can you tell us a bit about being a health visitor?}

Ann: There is a core programme for health visiting, which varies slightly from area to area, but in my case I routinely visit new babies 10-14 days after birth, then six weeks after birth, three to four months after birth, at eight months for a development check by our team and then again officially for a development check around two to two-and-a-half years. We also hold informal clinics twice a week where people can access help from a health visitor without needing an appointment. Health visiting has changed slightly over the years as now we work corporately as a team whereas we used to be linked to GPs and would see families more often but unfortunately there aren't enough health visitors at the moment.

Strictly speaking being a health visitor is health promotion. All our information has to be research-backed from sources like the World Health Organisation or the Department of Health and it's about giving people the facts, promoting optimum health, lifestyles and informed choice. We don't act as police monitoring people; it's about encouragement. In my area we work a lot with quite young and vulnerable families, very often single mums who have not had a very good experience of parenting themselves so need quite a bit of input. We also have a lot of interaction with child protection and you have to be aware of the progressing levels of concern around a child. If a child is identified as vulnerable and multi-agency intervention does not resolve the concerns, then it will become more formalised as a child protection case. The idea is to intervene early so it doesn't get to child protection - prevention is always better.

We monitor children's development and if there are any concerns then we can refer to the relevant person, like a speech therapist for example. It's a very varied job and we can give families a lot of input if it is needed.

\section{Laura: What oral health advice do you give parents?}

Ann: It varies considerably. Some have read every book they can get their hands on but are confused as all the books give slightly different advice, while others don't even access antenatal care. Sometimes it's almost as if the mothers are in denial that they're actually pregnant though most do access antenatal care even if it's not high in their priorities.

One of the main problems we have is that parents put juice in feeding bottles, which is one of the worst things you can do as far as oral health is concerned. It can be very difficult to try to get through to the parents that if they carry on with this practice then their child is probably going to have dental decay before they go to school. Many are more vigilant now when it comes to children's teeth but there's still a lot of work to do and we frequently have to remind them about avoiding the number of times they give their children sugary substances. It's probably slightly different where we

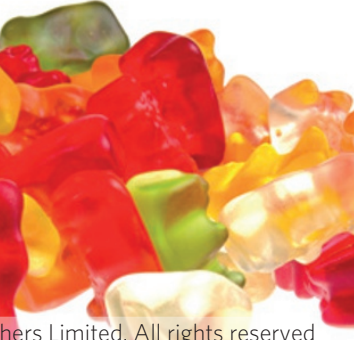




\section{'Often parents think it doesn't}

\section{matter if they're just baby teeth, so}

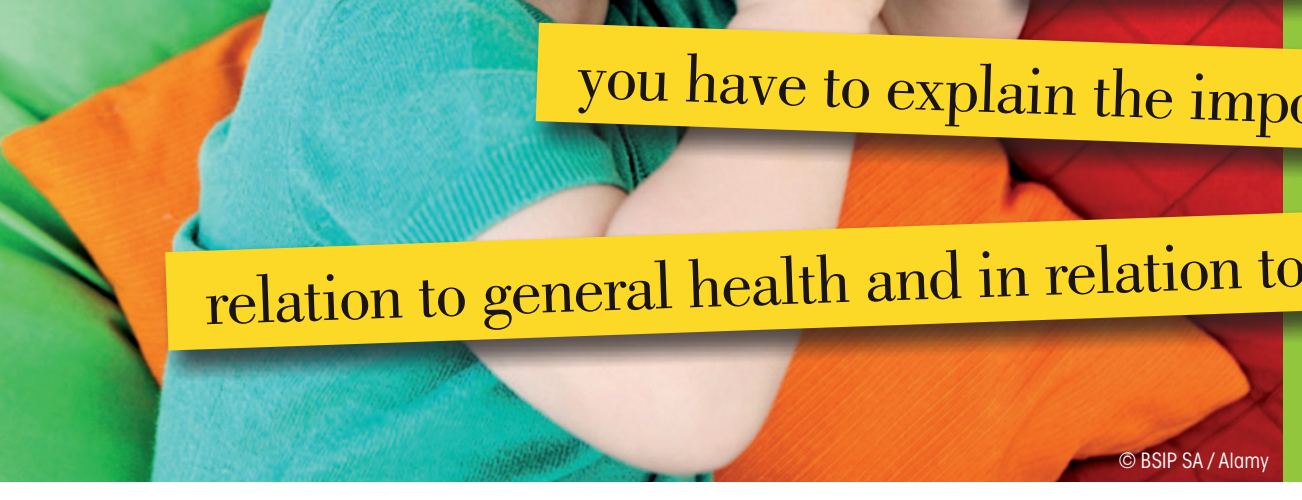

but we encourage the use of family toothpaste for children rather than children's toothpaste because there's not enough fluoride in it. We've always said it doesn't matter that the child can't rinse its teeth and now of course we know it's okay to leave the toothpaste on because why would you use fluoride and then rinse it off? We advise that toothpaste is left on the teeth.

\section{Laura: Has the oral health advice you} give changed greatly over the years?

Ann: It's not changed that much since 1999

when I first started working as a health visitor. In general it's the weaning advice that changes. It's now six months before they recommend weaning but originally it was three months and then it was four months. The new recommended weaning age is something that is often hard for new parents to accept because some grandmas are still saying they need weaning before then. They claim to have weaned their children at two months, for example, without it doing any harm, so the main thing is not to antagonise and try and get grandma on your side - you get a lot further! You have to give the rationale behind why you're saying what you're saying and then they have to make their own informed choice. Again, we're not policing it and don't take them to task if they don't follow official guidelines exactly.

\section{Laura: What do you look for in}

\section{assessing dental neglect in children?}

Ann: It's part of the general assessment and has been stressed particularly in the last couple of years. We don't actually open the mouth and have a look but in the general assessment you can gauge a child's oral health. If you can see there's a build-up of plaque or the gums are inflamed then you would be concerned. Often the parents have the same symptoms and it's quite a hard situation to handle if the mum has poor dental care; you have to be quite tactful when broaching that with the parents. It's best to take the attitude of 'I'm concerned there's some inflammation, do you have any problems?' Sometimes you get a parent who's frightened of the dentist or whose overall hygiene just isn't very good so dental hygiene's not high on their agenda either and they don't see the need for it for their children. But if they don't access dental care for their children then that's the same as not accessing medical care when they're ill - it is significant and serious. Often parents think it doesn't matter if they're just baby teeth, so you have to explain the importance of baby teeth in relation to general health and in relation to the second set of teeth that come through, as well as stress how decayed teeth may be causing pain at the time. We're lucky to have a community dentist at the local health centre that will see any children that we're worried about. She's quite flexible and that's important when we have concerns about children accessing dental care.

\section{Laura: What do you think parents} struggle with most in terms of looking after their child's dental health?

Ann: Finding a NHS dentist in the area is a major problem. Also avoiding lots of sugary things. Some parents give them lots of sweets and fruit juice - they don't seem to understand that water is perfectly okay and think it's mean to give water because they themselves don't like it. Even though most know there should be a routine of brushing teeth twice a day, if a child objects they won't pursue it. You have to explain that they're the adult and know what's best, so even if the child is saying they don't want to do it the parent has to persevere. The majority of parents can't understand the damage being done because it can't be seen so it's not immediately obvious that not brushing teeth is doing harm.

\section{Laura: What do you think can} be done to improve oral health awareness among parents?

Ann: Probably if the information was presented on television, perhaps in adverts, people would believe it. I don't think Change4Life has really had an impact on the majority of the people I work with as I don't think they fully understand what it's about. The majority aren't going to go the website to look up healthy recipes and lifestyle options. I do think something high profile and simple, focusing on just one specific piece of information on a regular basis for a set period, would have quite an impact. Short educational pieces between programmes would probably be too expensive.

\section{Laura: What would be your five} top tips to new parents on feeding, weaning and dental health?

Ann:

- Start as you mean to go on

- Don't let the child rule the household. A new baby does change a household but you have to encourage some kind of routine to fit in with the rest of the family

- Stick to breast or formula milk for the first six months; don't be tempted to wean early

- Prepare your own food. If you don't buy commercial food and make it yourself then you've got control over the amount of sugars and salt in the meal

- Avoid giving sugary snacks - sometimes you see a child with a drink on the go all day and constantly eating sweets and biscuits. This is a fast track to tooth decay. 